\title{
12
}

\section{Understanding Surface Drainage for Flood Control in Downtown Ottawa}

\author{
Manon N. Lalonde and Chris K. Rogers
}

A flood control study was carried out on a combined sewer area in the City of Ottawa. The study involved the development of detailed hydrologic and hydraulic models, using state-of-the-art GIS and stormwater management system simulation tools. Exploiting the limited opportunities provided by a highly urbanized environment and taking advantage of the urban infrastructure renewal program, the solution involves a significant volume of distributed in-line storage, sewer and major system diversions, inlet restriction, and temporary storage in two parks. Understanding the existing surface drainage patterns, site constraints and opportunities was a key component to creating efficient flood relief alternatives.

This chapter presents the model development of the existing combined sewer system and the approach used in developing a flood control solution.

\subsection{Introduction}

The study area in downtown Ottawa has a long history of flooding. Over the years, drainage improvements have been identified and implemented in piecemeal fashion as part of the City's infrastructure renewal program. However, in 2005 the City initiated a Class Environmental Assessment (EA)

Lalonde, M.N. and C.K. Rogers. 2007. "Understanding Surface Drainage for Flood Control in Downtown Ottawa." Journal of Water Management Modeling R227-12. doi: 10.14796/JWMM.R227-12.

(C) CHI 2007 www.chijournal.org ISSN: 2292-6062 (Formerly in Contemporary Modeling of Urban Water Systems. ISBN: 0-9736716-3-7) 
Study of the drainage system, in order to identify a comprehensive flood control solution that would increase the level of service (LOS) within the study area. The LOS objective is to keep the system hydraulic grade line (HGL) below basement levels for the selected 100 year design event.

\subsubsection{Study Area}

The study area, as shown in Figure 12.1, covers about 315 ha and is roughly bounded by Somerset Street to the north, Bronson Avenue to the west, the Rideau Canal to the east and Fourth Avenue to the south. Prior to settlement, the area included the headwaters of Patterson Creek which drained eastward to the Rideau River. The Rideau Canal intercepted the creek when it was constructed in the early 1820s. Over the years, the creek was shortened to end near O'Connor Street and a landscaped Central Park replaced the original creek bed from O'Connor Street to Lyon Street.

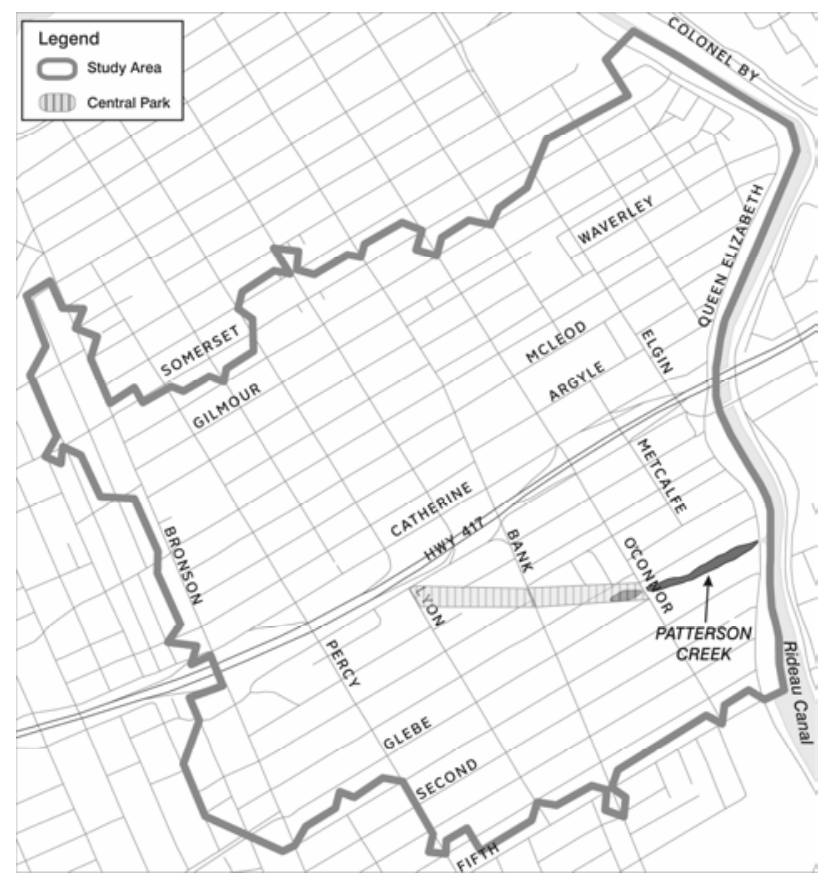

Figure 12.1 Study area. 
The original combined trunk sewer system, designed to provide a two year LOS, was built in the 1890s, discharging to the Rideau River near Somerset Street. In the 1930s, the Rideau Canal Interceptor (RCI), a 2,200 $\mathrm{mm}$ diameter pipe, was constructed parallel to and on the west side of the canal to divert the sewer flows to the Ottawa River (Figure 12.2). Today, approximately 2.5 times the average dry weather flow is intercepted by the main Interceptor-Outfall Sewer at Wellington Street and carried to the City's sewage treatment plant. Combined sewer overflows (CSO), i.e. flows exceeding the interceptor capacity, are discharged into the Ottawa River.

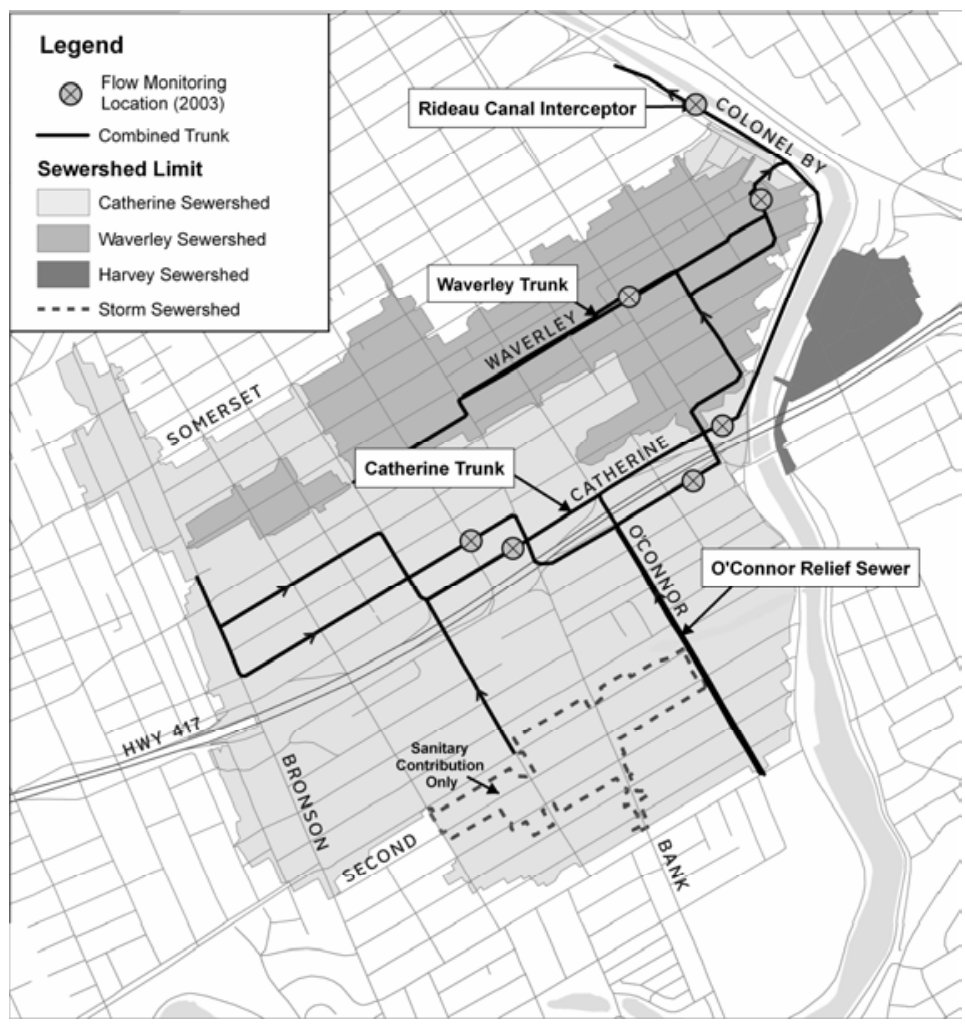

Figure 12.2 Trunk sewer system.

Two principal combined sewer trunks connect to the RCI: a 1,800 mm diameter pipe along Catherine Street, and a 1,100 mm diameter pipe along 
Waverley Street. The Catherine trunk services approximately $75 \%$ of the study area. Today, a 14 ha separated storm sewer system drains to Patterson Creek, but most runoff from the remainder of the area is captured by the combined sewer system and conveyed north by the RCI. The City is not considering any further sewer separation in the area as a real time control system is currently being examined to achieve CSO reduction targets.

\subsubsection{Flooding Problems and Modeling Needs}

Urbanization has incrementally introduced new constraints to overland flow by altering drainage patterns, and as imperviousness increased, flooding problems arose. While surface flooding can be problematic in rare events, particularly relating to traffic movement on arterial roads, the main problem is basement flooding caused by sewer surcharge. Multiple basement floodings due to overtaxation (exceedance of conveyance capacity) have been estimated to occur at a 2 y frequency, and surface flooding of private property is also of concern. During the August 8, 1996 event (a storm with an estimated $0.2 \%$ probability of occurring once in any given year, i.e. a 500 y event), over 480 flooding complaints were filed with the City because of overtaxation of the sewer system. Traffic on arterial roads was also impeded, with up to $2.5 \mathrm{~m}$ ponding at a key intersection.

The area is relatively flat and includes seventeen significant land-locked depressions where runoff accumulates, leading to surface flooding, particularly north of the Queensway (HWY 417). The combination of high catchbasin density and runoff ponding in the land-locked depressions can lead to high rates of inflow to the sewer network. The sewer system is highly interconnected, with many flow diversion structures. Overall, the drainage system is complex, necessitating much analytical effort to identify an optimal and comprehensive flood control solution.

\subsection{Model Development}

\subsubsection{Modeling Approach}

The approach taken to analyzing the existing drainage system and identifying flood control measures at the scale of both the local and trunk sewers was to develop a very detailed (i.e. block-by-block) model of the system. 
One key requirement for the model was to permit simulation of the actual capture of runoff into the existing sewer system, while adequately representing surface routing along streets and within land-locked depressions. The Dual Drainage Storm Water Management Model (DDSWMM) has such ability and allows for efficient computations with reasonable accuracy (AMK Associates International Ltd., 1997). Surface runoff is calculated following a methodology developed for the EPA SWMM Model (Huber et al, 1988). Catchment runoff is considered as an inflow into the street network. Unsteady flow routing of overland flow along the streets is based on the kinematic wave model, with a numerical solution approximating a diffusion wave model. Results are accurate as long as two assumptions are met: (i) there is no significant backwater effect, and (ii) the networks are dendritic and converge toward a downstream outlet(s). Following routing, an inlet sub-model computes the overland flow that is captured by the catchbasin (CB) inlets. The overland flow that is not captured is carried over to the next downstream street segment.

In DDSWMM, flow routing in sewers is based on free surface flow assumptions. If inflows into the sewers cause surcharge conditions, DDSWMM will either limit the flow access into sewers or revise the pipe sizes such that free flow conditions prevail. Because of these assumptions, the minor system sub-model in DDSWMM could not be used. The simulation of a complex sewer system that operates under surcharge conditions required a more powerful model for the pipe hydraulic analysis. A model capable of performing dynamic wave routing was essential, and the EXTRAN module (hydraulic layer) within XP-SWMM (XP Software Inc.) was selected. Although using two separate models to represent the drainage system precluded the dynamic interaction of linked minor and major systems, this limitation was seen as inconsequential because of the limited interactions between the two systems in key study components. For instance, the model calibration was to be performed with events that did not result in sewer surcharges to the ground level, and the flood control solution required that sewer surcharge be maintained below basement level.

Given the large study area and the need for a block-by-block analysis, MapInfo Professional (MapInfo Corporation, 2004), a GIS tool, was used to facilitate data compilation and manipulation. The surface drainage analysis was facilitated with Streambuilder, an extension for MapInfo Professional, which builds stream networks and drainage basins directly from a digital elevation model (DEM). 


\subsubsection{Input Data}

\section{DDSWMM Model Development}

The modeling exercise used three of the four DDSWMM sub-models: (i) the surface runoff sub-model (ii) the inlet sub-model, and (iii) the major system sub-model. The minor system sub-model was not used. Instead inlet hydrographs were exported to XP-SWMM using an interface file.

The first step in the model development was the discretization of the surface catchment area. Using a DEM, Streambuilder was used to automatically generate surface flow patterns for conditions where all the land-locked depressions are full of water and spilling towards the downstream outlets. Limiting the basin maximum size to 0.5 ha resulted in a "block-size" discretization for sub-catchments. Sub-catchment boundaries were further adjusted in consideration of specific sewer segments based on the road network and the property parcel fabric. Approximately 450 subcatchments were created through the discretization process.

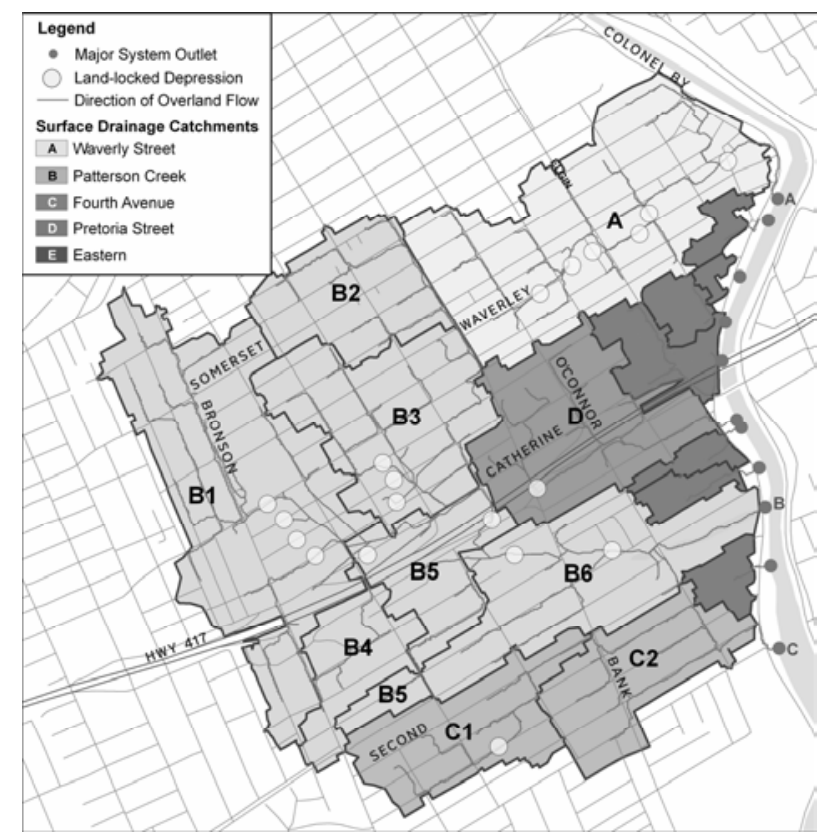

Figure 12.3 Surface drainage. 
Through this exercise, four principal catchment areas were identified within the study area, with outlets in Patterson Creek and the Canal (Figure 12.3). Catchment size varies between 30 and 175 ha. There are also a number of minor catchment areas along the eastern boundary of the study area with overland flow draining into the Canal.

The flow paths determined by Streambuilder were the basis for establishing the major system connectivity. Working with $0.1 \mathrm{~m}$ contour lines, seventeen land-locked depressions that obstruct major system connectivity were identified. Using specific capture-storage relationships, each depression was represented as a storage inlet in the inlet sub-model.

The characteristics of the system were defined as summarized in Table 12.1, Table 12.2 and Table 12.3.

Table 12.1 Sub-catchment characterization. (surface runoff sub-model)

\section{CHARACTERISTIC}

Imperviousness

- Nine major land uses were found within the study area based on GIS information;

- Ratios of various land uses within each sub-catchment area were determined;

- Representative areas for each land use were visited on-site to measure directly connected impervious areas (DCIA); and

- An area weighed average for the DCIA parameter was assigned to each subcatchment based on the land use ratios.

Flat Roofs

- Surface area attributed to flat roofs within each sub-catchment were estimated based on land use ratios and field investigations; and

- Sub-catchments with more than $40 \%$ of surface area consisting of flat roofs were modeled as separate sub-catchments with DCIA $=100 \%$. Assuming a $150 \mathrm{~mm}$ roof drain diameter, the capture rate was assumed to be on a 1:1 basis, up to the 10 year event. Above that, roof runoff is spilling on the ground.

Sub-catchment Width and Slope

- Initial "width" parameter value was set to one or two times the roadway width depending on whether lots are draining to the street from one or two sides; and

- Sub-catchment slopes, determined on the basis of representative areas, vary between 1.5 and $2 \%$. 
Table 12.2 Catchbasin inlet characterization (inlet sub-model).

\section{CHARACTERISTIC}

Regular Catchbasin Inlets

- City database contained partial information on number and location of CBs;

- Streets with missing information were field checked for $C B$ location and type.

- Over 4,900 CB inlets are represented;

- Nine capture curves for regular inlets were coded in DDSWMM representing combination of three inlet types ( fishbone, standard and curb inlet) and three street longitudinal slopes ranging between 0.6 and $1.4 \%$; and

- Inlet Control Devices (ICD's), generally consisting of perforated plates installed in the catchbasin lead, are in place in several locations. These were identified in the DDSWMM coding.

Land-Locked Depressions

- Depressions were modeled as inlet storages. Stage-storage relationships were generated based on the DEM of the study area.

- Type of CB inlets within ponding areas were all field checked. Special stagecapture relationships were derived accounting for ponding depth at each individual CB inlet; and

- At maximum ponding depth, maximum capture was generally governed by the CB lead.

Table 12.3 Major system characterization (major system sub-model).

\section{CHARACTERISTIC}

Roadway Characterization

- Two typical roadway widths from curb to curb: $9 \mathrm{~m}$ wide on local roads, $14 \mathrm{~m}$ on arterial roads;

- Study area was divided in four areas with similar topography. Roadway longitudinal slopes across study area varied between 0.6 and $1.4 \%$;

- Typical pavement cross-slope is $\mathrm{Sx}=2 \%$. Typical shoulder slope is also $2 \%$, but several streets have shoulder on one side actually lower than the curb elevation; and

- Overall, seven typical roadway types were defined to represent various roadway conditions encountered within the study area.

\section{XP-SWMM Model Development}

The main input to the XP-SWMM (EXTRAN) model was derived from a sewer database provided by the City. After reviewing the pipe connectivity with MapInfo, the pipe database was imported into the model using XP-GIS. 
Input data was verified in critical areas based on a review of record drawings, site inspections, and examination of sewer profiles within the hydraulic model. Testing the model with dry weather flow conditions revealed a number of data errors, which were resolved by additional field investigations. Data errors included pipe inverts and the presence of diversion weirs, which influenced the direction of flow.

More than fifteen hydraulic structures were modeled, many involving bulkheads located immediately downstream of side overflow weirs. The bulkheads were simulated using rating curves developed using Manning's equation for low flow, and the orifice flow relationship for high flow conditions. The explicit modeling of side overflow weirs generated instabilities in the simulation; hence, they were generally simulated using short, steep rectangular pipe elements with upstream inverts equal to the weir elevation.

In total 1,000 pipes were represented in the model. Brick sewers were assigned a default Manning's $n$ value of 0.016 , and concrete was assigned a default value of 0.013 . The pipe node identifications in the XP-SWMM model were referenced in the DDSWMM model so that hydrographs generated by the latter could be imported to the appropriate location in the former.

\subsubsection{Model Calibration and Validation}

Flow monitoring data collected by the City at six locations along the trunk sewer network in 2003 (Figure 12.2) was used to calibrate the model. Prior to calibration, the monitoring data was reviewed and screened. Two of the events used for calibration resulted in surcharged conditions at three of the monitoring locations. All reported surcharges were below ground level and did not require model interaction between XP-SWMM and DDSWMM.

Because a high level of effort was used in characterizing the most sensitive parameters, only a few DDSWMM model parameters needed adjustment as part of the calibration process. Three parameters were adjusted to achieve a satisfactory calibration: (i) flat roof depression storage and catchment width, (ii) catchment width in the Waverley system to represent longer travel times within a mixed land use area, and (iii) imperviousness in some localized areas. Two XP-SWMM model parameters were adjusted including the discharge coefficients used in some hydraulic structure rating curves and the Manning's $n$ in part of the system to simulate higher local loss due to pipe conditions. 


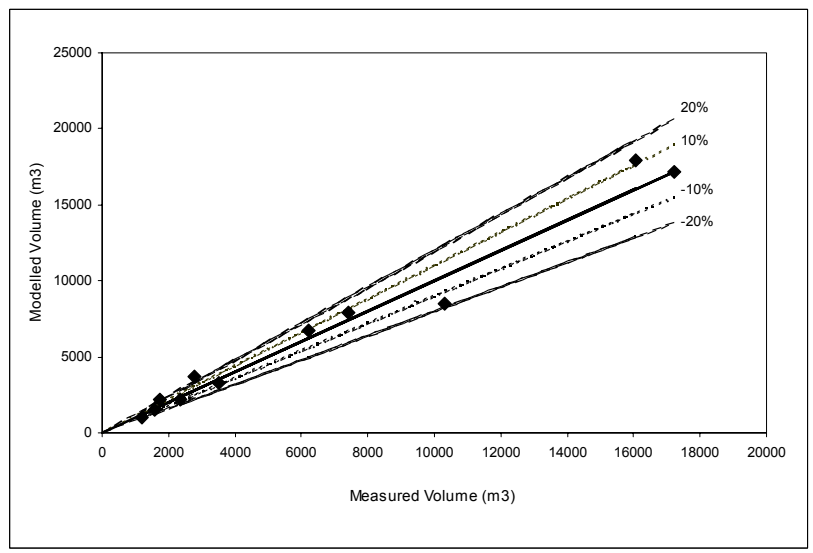

Figure 12.4 Calibration results - peak flow.

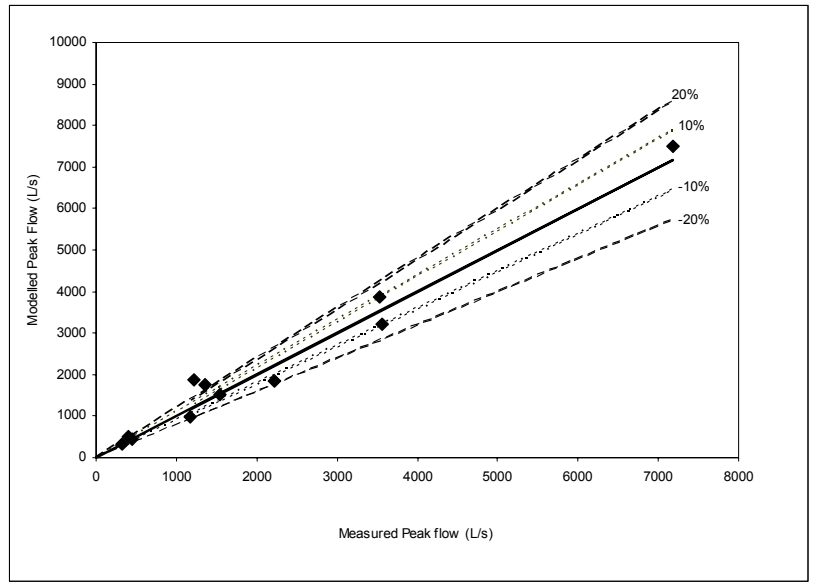

Figure 12.5 Calibration results - peak volume.

The success of the calibration is illustrated by flow and volume scattergraphs given in Figure 12.4 and 12.5. Based on an analysis of point rain gauge data (station located about two kilometres from the centroid of the drainage area) and radar rainfall data, it was found that the small differences between the measured and modeled flows and volumes could be 
entirely explained by inaccuracies in rainfall input data. Both data sources have limitations in accurately representing the high intensity, spatially varied rainfall events that tend to generate critical conditions in the sewer system.

To verify the model, the simulated peak HGL along the RCI resulting from the August 8, 1996 critical historical event was compared to high water marks measured at several maintenance holes $(\mathrm{MH})$ along the sewer, immediately following the event. Differences between simulated and observed HGLs were small, ranging between 0 and $5 \%$ in the upstream end of the sewer; they were larger, ranging between 5 and $20 \%$, in the downstream end. These differences concur with the expected effect of having a non-dynamic model of the minor and major system interaction (due to the use of two separate models). For rare events such as the 1996 storm, this modeling limitation would tend to overestimate runoff capture rates and sewer surcharges.

\subsection{Existing System Performance}

A sensitivity analysis using synthetic design storms of various distributions and durations was conducted with the calibrated model to define the most conservative design event. The Soil Conservation Service of America Type II $6 \mathrm{~h}$ storm event was found to generate the highest HGLs within the sewer network for the $100 \mathrm{y}$ conditions and was hence selected as the $100 \mathrm{y}$ design event for this study. The $1 \mathrm{~h} 30 \%$ AES (formerly Atmospheric Environment Services) was found as the most conservative event for the more frequent events, i.e. for the $2 \mathrm{y}$ and $5 \mathrm{y}$ design events.

Simulations with the calibrated model were conducted using the selected design events to assess the performance of the existing system. Given that the system was designed to have a 2 y capacity, it was expected that the HGL would be near the pipe obvert throughout the system for design events of this frequency. This was found generally to be the case. For the $5 \mathrm{y}$ design event, almost $30 \%$ of the roughly $1,000 \mathrm{MHs}$ represented in the model were found to surcharge to basement elevation or higher, and about $3 \%$ of MHs were found to surcharge to ground level. For the $100 \mathrm{y}$ design event, almost $70 \%$ of MHs surcharged to basement elevation, and almost $20 \%$ surcharged to ground level, with significant volumes of combined sewage spilling onto the ground surface.

DDSWMM modeling results highlighted the difference in peak capture rates, i.e. runoff inflows to the sewer system, on streets with continuous 
slopes and those where land-locked depressions exist. Peak capture rates, as computed by DDSWMM inlet sub-model, for over 365 street segments with continuous slopes and 17 street segments with land-locked depressions were averaged for the exercise. The average street segment length was $130 \mathrm{~m}$ and the average number of CB inlets was 6.6 per street with continuous slopes and 9.5 per street with land-locked depressions. As shown in Table 12.4, the average peak capture rates on streets with land-locked depressions can be several times larger (as much as three times larger for extreme events) than capture on streets with continuous slopes. On continuously sloped streets, the peak captured runoff during a $100 \mathrm{y}$ design event is twice as large as for a 2 y design event. On streets with land-locked depressions, the $100 \mathrm{y}$ design event leads to an average peak capture rate as much as four times that of the 2 y design event.

Table 12.4 Average runoff capture rate on streets.

\begin{tabular}{ccc}
\hline Design Event & $\begin{array}{c}\text { Average Peak Capture on } \\
\text { Streets with Continuous Slope } \\
(\mathrm{L} / \mathrm{s})\end{array}$ & $\begin{array}{c}\text { Average Peak Capture on } \\
\text { Streets with Land-Locked } \\
\text { Depressions } \\
(\mathrm{L} / \mathrm{s})\end{array}$ \\
\hline $2 \mathrm{y}$ & 60 & 100 \\
$5 \mathrm{y}$ & 80 & 160 \\
$100 \mathrm{y}$ & 130 & 400 \\
\hline
\end{tabular}

While the poor system performance under infrequent events can in part be attributed to the lack of a continuous major system, it is also clear that the inlet capacity of the system is well in excess of the 2 y sewer system capacity. The simulation results suggest more potential flooding problems than indicated from flooding complaints. However, the completeness of the City's flooding database is uncertain, and it is known that many property owners do not report flooding incidences.

Examination of the major system for the $100 \mathrm{y}$ design event shows that several land-locked depressions would fill up and spill over. Results indicate that a very large volume of surface runoff and spilled sewage is likely to collect in Central Park under extreme conditions. This finding is consistent with observations from the August 8, 1996 event. Overland flow peak discharges at outlets in the Canal vary between 0.5 and $2.0 \mathrm{~m}^{3} / \mathrm{s}$, with catchments that have no land-locked depressions tending to generate higher rates. 


\subsection{Flood Control Solution}

\subsubsection{Alternative Solutions Development}

A number of potential primary and secondary flood control measures that could be applied in various ways were identified. Before formulating alternative solutions, a basic understanding of the effect of flood control measures on the system was required. The potential performance for the measures was evaluated using two simple tests that gauged the effect of relieving surcharge with measures applied either locally or at the trunk level. These tests applied extreme control and relief conditions to emphasize the response within the system.

The "local relief" test involved the use of inlet restrictors applied uniformly across the study area at a rate of $10 \mathrm{~L} / \mathrm{s}$ per catchbasin, corresponding on average to $50 \%$ of the estimated 100 year capture rate. For this test, continuous major system connectivity to the outlets was assumed to exist with a maximum ponding depth of $0.3 \mathrm{~m}$ at intermediate land-locked depressions. The "trunk relief" test involved the addition of several outlets along the major trunks to simulate surcharge relief via diversion sewers, with the overall effect of lowering the HGL within the trunk to the obvert elevation. While both tests yielded significant decreases in surcharge across the system, they also led to the identification of many sub-drainage areas that responded either to trunk relief or local relief measures. This classification helped to narrow down the potential flood measures for different part of the study area.

System configuration, significant inflow entry points and sub-system response time were considered in the development of alternatives. As well, opportunities for surface storage, inlet restriction, major system diversions, internal sewer diversions, and sewer separation with relief to existing stormwater outlets were identified and tested. Significant opportunities to control costs and construction impacts were provided by the City's infrastructure renewal program. A large potential surface storage capacity was also identified at Central Park. Once a part of Patterson Creek, the park is well below the grade of adjacent streets and properties.

A number of key constraints to potential flood control measures were also identified including: a prohibition against new minor system discharges to the Rideau Canal; the need to avoid works on roads that have recently been reconstructed; the need to avoid increases in overland flow on the large 
number of arterial roads; and the need to delay or prevent the accumulation of overland flow in land-locked depressions.

The information yielded from model testing, system analysis, and evaluation of opportunities and constraints was used to develop eight alternative solutions. These alternatives were evaluated in the context of the Municipal Class EA process, ultimately meeting Phase 1 and 2 requirements. This process requires that existing environmental conditions be defined, impacts on all aspects of the environment be evaluated, and potential mitigation measures be identified. Cost estimates and operation and maintenance requirements were also identified. Three separate committees were involved in overseeing the EA process: a Technical Advisory Committee consisting primarily of City staff, an Agency Stakeholder Committee, and a Public Advisory Committee. Two public open houses were conducted to obtain broader input from the community.

\subsubsection{Preferred Solution}

Alternative solutions were evaluated on the basis of fifteen criteria representing bio-physical, social, level of service and economic aspects. The preferred solution consists of a combination of local and trunk level measures, which are illustrated on Figure 12.6. The following key trunk level measures were part of the proposed solution:

- a new combined relief sewer for the Waverley system;

- diversion of the upstream part of the Waverley catchment (Florence at Bank) to the Catherine system, and elimination of the overflow structures at Lyon/Florence and at Cartier/Waverley;

- combined storage pipes with downstream throttles along several trunk sewer lines; and

- connection of additional "surge" storages to the Catherine trunk sewer.

An optimal combination of local relief measures that capitalizes on inlet control opportunities and local underground storm storage pipes was recommended. South of the Queensway, where there are few arterial roads, ICD's are proposed to restrict runoff entry into the sewer system at a rate of $10 \mathrm{~L} / \mathrm{s} / \mathrm{CB}$. Key surface drainage diversions divert overland flow away from land-locked depressions and into Central Park, where it is detained until it can drain back into the sewer system. Many streets located in the area north of the Queensway are to be rehabilitated in the future. Sewer separation on 
these streets, combined with controlled storage within the storm sewer, provide additional relief to the trunk system and result in the down-scaling of major flood relief measures. Street storage systems for overland flow were considered as an alternative to underground storm storage systems, but they were not retained because of existing grade constraints.

With the recommended design, the LOS was met for most of the drainage area. In some local areas however, a $100 \mathrm{y}$ event criteria was impractical to achieve. The HGL for these areas were generally below basement level for the City's 25 y event.

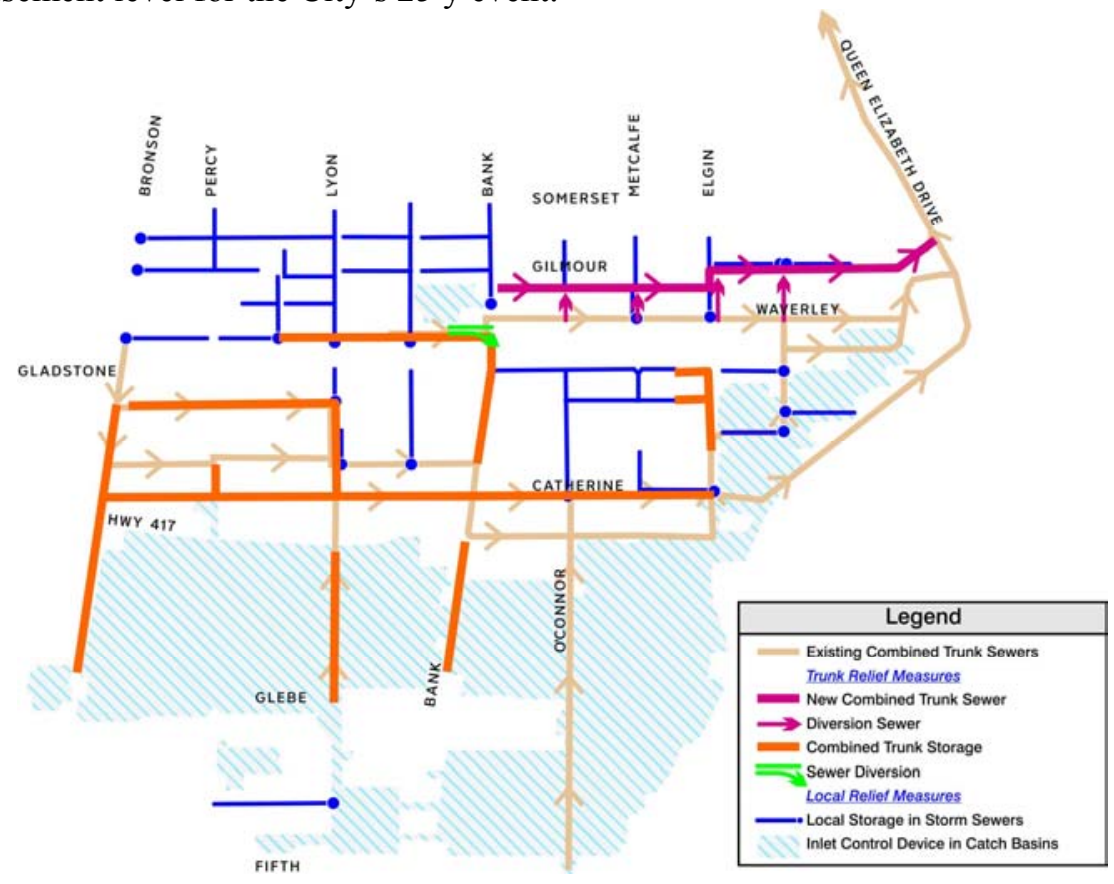

Figure 12.6 Preferred solution.

\subsection{Conclusions}

A block-by-block hydrologic and hydraulic model of an overtaxed combined drainage system in Downtown Ottawa was developed to identify a comprehensive flood control solution. The existing drainage system, 
designed in the $1890 \mathrm{~s}$, was designed without major system considerations, which resulted in several surface drainage limitations. Combining a DEM of the area with a commercially available GIS tool provided an accurate representation of overland flow patterns in this urban area. This information was critical to accurately establishing major system drainage patterns and performance, and facilitating the development of an inlet restriction and major system diversion plan that would not negatively impact private properties.

The very detailed system analysis allowed the development of optimal alternative solutions that could not have been appropriately sized and configured with a trunk level study. Given the complexity and scope of the solution, further refinement of the solution is being carried out, and a detailed phasing plan is being developed that will be integrated with the City's rehabilitation program. The phasing strategy will be based on implementing the most effective flood control measures early in the program, and avoiding negative impacts that would result from poorly sequencing certain elements of the solution.

\section{Acknowledgments}

This study was funded by the City of Ottawa. We appreciate the efforts of the City project manager, Mr. Patrick Leblanc, in actively participating in the study and supporting cooperative efforts with City staff that were needed to achieve the results documented in this chapter.

\section{References}

AMK Associates International Ltd., 1997. Dual Drainage Storm Water Management Model, Program Documentation and Reference Manual, Release 2.

Huber, W. C. and R.E. Dickinson, 1988. Storm Water Management Model, Version 4 User's Manual. US Environmental Protection Agency.

MapInfo Corporation, 2004. MapInfo Professional Version 7.8, Release Build 17. Troy, New York. 